OPEN ACCESS

Edited by:

Kalpna Gupta,

University of Minnesota Twin Cities, United States

Reviewed by: Kempuraj Duraisamy, University of Missouri, United States Illkka Harvima, University of Eastern Finland, Finland

*Correspondence: Gary K. Steinberg gsteinberg@stanford.edu

Received: 30 January 2019 Accepted: 13 March 2019 Published: 03 April 2019

Citation: Arac A, Grimbaldeston MA, Galli SJ, Bliss TM and Steinberg GK (2019) Meningeal Mast Cells as Key Effectors of Stroke Pathology. Front. Cell. Neurosci. 13:126. doi: 10.3389/fncel.2019.00126

\section{Meningeal Mast Cells as Key Effectors of Stroke Pathology}

\author{
Ahmet Arac ${ }^{1}$, Michele A. Grimbaldeston ${ }^{2}$, Stephen J. Galli ${ }^{3,4}$, Tonya M. Bliss ${ }^{5,6}$ \\ and Gary K. Steinberg ${ }^{5,6 *}$
}

\begin{abstract}
'Department of Neurology, David Geffen School of Medicine, University of California, Los Angeles, Los Angeles, CA, United States, ${ }^{2} \mathrm{OMNI}$-Biomarker Development, Genentech Inc., South San Francisco, CA, United States, ${ }^{3}$ Department of Pathology, School of Medicine, Stanford University, Stanford, CA, United States, ${ }^{4}$ Department of Microbiology and Immunology, School of Medicine, Stanford University, Stanford, CA, United States, ${ }^{5}$ Department of Neurosurgery, School of Medicine, Stanford University, Stanford, CA, United States, ${ }^{6}$ Stanford Stroke Center, School of Medicine, Stanford University, Stanford, CA, United States
\end{abstract}

Stroke is the leading cause of adult disability in the United States. Because post-stroke inflammation is a critical determinant of damage and recovery after stroke, understanding the interplay between the immune system and the brain after stroke holds much promise for therapeutic intervention. An understudied, but important aspect of this interplay is the role of meninges that surround the brain. All blood vessels travel through the meningeal space before entering the brain parenchyma, making the meninges ideally located to act as an immune gatekeeper for the underlying parenchyma. Emerging evidence suggests that the actions of immune cells resident in the meninges are essential for executing this gatekeeper function. Mast cells (MCs), best known as proinflammatory effector cells, are one of the long-term resident immune cells in the meninges. Here, we discuss recent findings in the literature regarding the role of MCs located in the meningeal space and stroke pathology. We review the latest advances in mouse models to investigate the roles of MCs and MC-derived products in vivo, and the importance of using these mouse models. We examine the concept of the meninges playing a critical role in brain and immune interactions, reevaluate the perspectives on the key effectors of stroke pathology, and discuss the opportunities and challenges for therapeutic development.

Keywords: meninges, mast cells, ischemic stroke, meningeal mast cells, stroke pathology

\section{INTRODUCTION}

Every year, $\sim 800,000$ people suffer from stroke in the United States (Benjamin et al., 2018). The currently available therapies for acute stroke focus on removal of the blood clot, either pharmacologically or mechanically (Fisher and Saver, 2015). With advances in careful patient selection for these therapies, the time window for therapy initiation can be extended up to $24 \mathrm{~h}$ (Albers et al., 2018; Nogueira et al., 2018). However, the majority of patients are still not eligible for these therapies. Ischemic stroke occurs when the blood supply to the brain is interrupted by a blood clot. This initiates a cascade of events that includes excitotoxicity, free radical release, mitochondrial changes, and various degrees of immune response that leads to neuronal and glial cell death, blood-brain barrier dysfunction and ultimately the clinical symptoms (Moskowitz et al., 2010; Knowland et al., 2014; George and Steinberg, 2015). The timing of these events differ, and additionally, the post-stroke immune response has different phases that can be detrimental or beneficial (Anrather and Iadecola, 2016). Thus, a detailed understanding of the post-stroke immune response is necessary in order to better utilize its therapeutic potential. 
The brain is long considered to be an immune-privileged organ (Louveau et al., 2015a). This is in part due to its anatomical isolation from the rest of the body, having its own unique resident immune cells (microglia), and having restricted access for circulating immune cells under homeostatic conditions. This is important for homeostatic functions but becomes especially important in pathological conditions. More recently, meninges - the membranes surrounding the brain-have been proposed to play important roles in the regulation of brainimmune interactions (Rua and McGavern, 2018). Emerging evidence suggests that the actions of immune cells resident in the meninges are important for the immunoregulatory role of the meninges (Rua and McGavern, 2018). Mast cells (MCs) reside in high numbers within the meninges. These tissue-resident immune cells have proinflammatory and immunoregulatory roles (Grimbaldeston et al., 2007; Biggs et al., 2010; Galli et al., 2011; Tsai et al., 2011), and play key functions in both innate and adaptive immune responses. They act as constitutive or inducible sources of many cytokines, chemokines and proteases (Mukai et al., 2018). This makes them potential targets for therapeutic intervention, depending on their roles in the pathophysiology. Fortunately, there are several methodologies to study the role of MCs and MC-derived products in vivo (Galli et al., 2015).

Here, we discuss the evidence that MCs located in the meningeal space can worsen stroke pathology. We also review some of the latest advances in mouse models to investigate the roles of MCs and MC-derived products in vivo, and the importance of using these mouse models. We examine the concept of the meninges playing a critical role in brain and immune interactions, reevaluate perspectives on key effectors of stroke pathology, and discuss the opportunities and challenges for therapeutic development.

\section{MENINGES AS KEY SITES FOR BRAIN IMMUNE ACCESS}

Meninges are the connective tissue that surrounds the brain and spinal cord. They consist of three layers (Figure 1): an outer thick layer, dura mater, that is attached to the skull, an inner thin layer, pia mater, that is attached to the brain and spinal cord parenchyma, and a spider net-like structure, arachnoid mater, in between the dura and pia maters. The blood vessels and the cerebrospinal fluid exist within the space between the arachnoid mater and pia mater (subarachnoid space). The meninges have long been considered as just an anatomical barrier; however, accumulating evidence suggests that they are important for brain-immune communications in health and disease (Androdias et al., 2010; Derecki et al., 2010; Shechter et al., 2013; Kwong et al., 2017; Benakis et al., 2018). All the arteries that penetrate the brain parenchyma first travel through the subarachnoid space before entering into the brain. The venous blood then travels along the sinuses within the dura mater before exiting the skull. Moreover, the recent discovery of the central nervous system (CNS)'s lymphatic vessels within the meninges highlights their potential role in brain-immune interactions (Aspelund et al., 2015; Louveau et al., 2015b). These meningeal lymphatics have been shown to be important in controlling both neuroinflammatory events and immune cell trafficking (Louveau et al., 2018b). Additionally, direct vascular channels that traverse the meninges have been discovered recently between the bone marrow in the skull and the

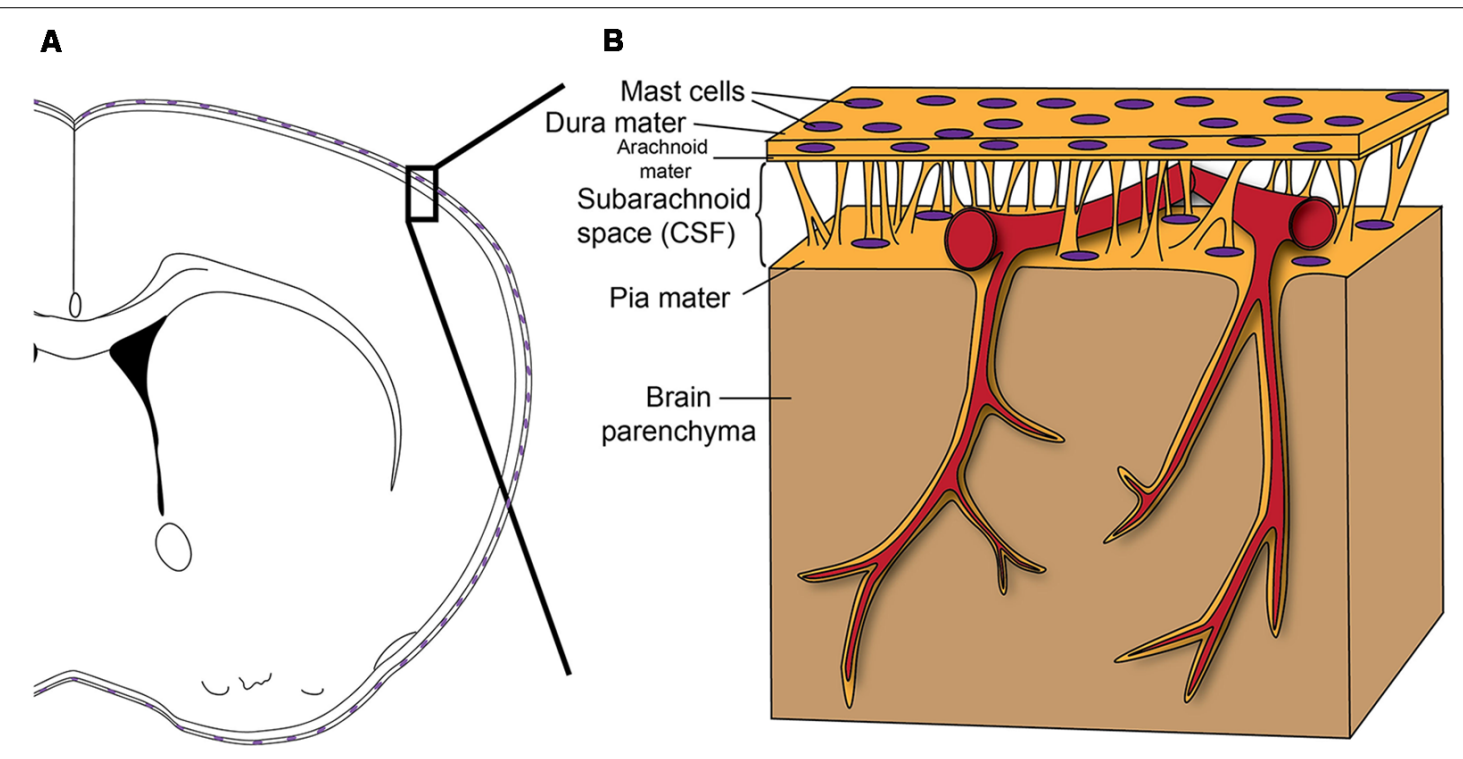

FIGURE 1 | (A) Scheme shows how the brain is enveloped by the meninges that contain Mast cells (MCs) in both the dura mater and pia mater. (B) Before entering the brain parenchyma, blood vessels course on the surface of the brain between the dura mater and pia mater. Therefore, as a resident immune cell in the meninges, the MC has the potential to influence blood vessels and to function as a gatekeeper to influence brain inflammation and pathology. Reprinted from Arac et al. (2014) with permission from Elsevier. 
brain surface (Herisson et al., 2018). These direct vascular channels help enable myeloid cell migration into the brain parenchyma in stroke (Herisson et al., 2018). All these vascular structures (the arteries and veins, meningeal lymphatic vessels, and direct vascular channels) travel through the meninges, making the meninges ideal for a possible gatekeeper role (Rua and McGavern, 2018).

While some immune cells locate to dura mater after stroke (Benakis et al., 2018) or aseptic inflammation (Kwong et al., 2017), there are also tissue-resident immune cells normally residing in the meninges. One such immune cell type is the MC (Dimlich et al., 1991; Arac et al., 2014; Figure 1). MCs are tissue-resident immune cells. Mature MCs do not circulate in the blood but exist especially in tissues exposed to the exterior, such as skin, lungs, and gut (Galli et al., 2011; Tsai et al., 2011). These regions are generally critical for host defense and require strong immune regulation, as they represent the interface between the body and the external environment (Galli et al., 2008). In this respect, it is not surprising that MCs exist at high numbers in meninges as the meninges separate blood and an immune-privileged brain parenchyma (Louveau et al., 2015a). Given the meninges' potential gatekeeper role in orchestrating brain-immune interactions, meningeal MCs can play significant roles in such interactions.

\section{CELLULAR ELEMENTS OF POST-STROKE INFLAMMATION}

Inflammation is critically important in stroke pathology. Several elements of the immune system play roles at different time points after stroke. The first immune cells to respond to interruption of blood flow to the brain are the resident microglia. There is evidence that microglia show signs of activation within $30 \mathrm{~min}$ to $1 \mathrm{~h}$ after stroke (Ito et al., 2001; Clausen et al., 2008); these changes evolve during the $12 \mathrm{~h}$ following stroke and result in decreased microglial numbers within $24 \mathrm{~h}$ (Ito et al., 2001). These changes persist several weeks after stroke onset (Lambertsen et al., 2005; Perego et al., 2011). The microglia secrete several pro- and anti-inflammatory cytokines and chemokines (Clausen et al., 2008; Lambertsen et al., 2009), and can be either detrimental (Neher et al., 2013) or beneficial (Lambertsen et al., 2009; Neumann et al., 2009) through secreted factors or direct phagocytosis.

One of the first immune cells that infiltrate the brain after stroke is the neutrophil. They start infiltrating around $6 \mathrm{~h}$ after stroke onset and reach peak numbers at $24 \mathrm{~h}$ (Perez-de-Puig et al., 2015). The predominant effect of neutrophils appears to be increased ischemic injury as inhibition of their trafficking results in better outcomes (Allen et al., 2012; Jickling et al., 2015; Neumann et al., 2015). However, there is also evidence that neutrophils play role in resolution of inflammation (Cuartero et al., 2013) and promotion of remodeling (Christoffersson et al., 2012) after stroke. Thus, the role of neutrophils in stroke pathology is more complex, which may in part account for the failure of translational approaches targeting neutrophils as stroke therapy (Jickling et al., 2015).
Monocytes follow neutrophils in parenchymal infiltration after a stroke, starting to infiltrate around 6-48 h after stroke onset and staying in the brain weeks thereafter (Lambertsen et al., 2005; Perego et al., 2011). The CCR2 ${ }^{+}$Ly6C high $^{\text {hig }}$ monocytes/macrophages are thought to be involved with the acute inflammation, thus worsening the damage, whereas CX3CR $1^{+}$Ly6 $C^{\text {low }}$ macrophages are considered as the immune cells involved in the repair process (Garcia-Bonilla et al., 2016; Tsuyama et al., 2018). However, monocyte response after stroke is very complicated. For example, the so-called inflammatory CCR2 ${ }^{+}$Ly6 $\mathrm{C}^{\text {high }}$ monocytes enter first, then are converted to regulatory $\mathrm{CX} 3 \mathrm{CR} 1^{+}$Ly6C ${ }^{\text {low }}$ macrophages (Garcia-Bonilla et al., 2016). Interestingly, efforts to target these monocytes populations have shown mixed results; reducing monocyte infiltration reduced stroke recovery in one study (Wattananit et al., 2016), while another study concluded that targeting monocyte subsets did not change the outcome after stroke (Schmidt et al., 2017).

The response of lymphocytes ( $\mathrm{T}$ and $\mathrm{B}$ cells) after stroke is quite different from that of the other immune cells as they tend to infiltrate the brain at later time points (days) and stay longer (weeks to months) after stroke onset (Liesz et al., 2013a). The role of these cells depends on the subtype of lymphocytes involved, for example, $\mathrm{T}$ cells can worsen the injury (Yilmaz et al., 2006; Clarkson et al., 2014; Mracsko et al., 2014). More specifically, regulatory $\mathrm{T}$ cells have been shown to be protective via secretion of interleukin-10 (Liesz et al., 2009, 2013b), whereas gamma-delta-T cells can worsen the injury by secreting interleukin-17 (Shichita et al., 2009). Moreover, targeting $\mathrm{T}$ cell infiltration by inhibiting their trafficking into the brain parenchyma protected the brain against deleterious neuroinflammation (Liesz et al., 2011b). However, amplifying regulatory T cells with a CD28 superagonist in preclinical studies have elicited conflicting outcomes, and resulted in reduced brain damage in one study ( $\mathrm{Na}$ et al., 2015), vs. increased brain damage in another (Schuhmann et al., 2015). Moreover, treatment with another immunomodulatory drug, FTY720, despite reducing the post-stroke lymphocyte infiltration after stroke did not improve the post-stroke outcomes (Liesz et al., 2011a). The role of B cells in stroke pathology is also very unclear. Although in some studies B cells did not have any direct effect on the stroke pathology (Yilmaz et al., 2006; Schuhmann et al., 2017), in others they were shown to be beneficial (Ren et al., 2011; Chen et al., 2012). However, B cells were also shown to have delayed deleterious effects such as cognitive impairment after stroke (Doyle et al., 2015).

MCs have been proposed to play important roles in stroke pathology. Specifically, cerebral MCs were shown to worsen the brain swelling and neutrophil accumulation after stroke (Strbian et al., 2006) and stroke induced the degranulation of brain parenchymal MCs (Biran et al., 2008; Jin et al., 2009; Lindsberg et al., 2010). Moreover, a MC stabilizer in rats, cromolyn, was shown to be protective in stroke (Strbian et al., 2007; Jin et al., 2009). Cerebral MCs were also shown to mediate blood-brain barrier disruption after stroke (Mattila et al., 2011; McKittrick et al., 2015). As opposed to these studies, 
which proposed a role for cerebral MCs in worsening stroke pathology, another study (reviewed in detail below), proposed that meningeal, rather than cerebral, MCs play important roles in exacerbating stroke pathology, in part by secreting IL-6 (Arac et al., 2014).

Overall, despite being a major participant in stroke pathology, inflammatory responses after stroke are complex, and attempts should be made to understand their detailed pathophysiological mechanisms before attempting therapeutic interventions.

\section{In vivo MODELS TO STUDY MC FUNCTION (“MC KNOCK-IN MICE")}

MCs are tissue-resident immune cells derived from bone marrow. Small numbers of MC progenitors exist in the blood, but they complete their differentiation and maturation in tissue microenvironments (Galli et al., 2008, 2011). MCs can be activated by diverse mechanisms including via binding of antigen to antigen-specific IgE (Galli and Tsai, 2012), as well as by physical agents, innate danger signals (Supajatura et al., 2002), venoms (Metz et al., 2006), complement activation (Schäfer et al., 2013), and exposure to certain chemokines and cytokines. Upon activation, MCs can secrete either stored mediators (such as histamine and heparin) or de novo synthesized cytokines, chemokines, and growth factors (Mukai et al., 2018). These MC-derived products have been shown to have positive or negative effects on inflammation (Galli et al., 2008). However, many of these MC-derived products are also produced by a variety of other immune cells.

In order to identify a role for MCs in different biological settings, one can ablate MCs selectively (either by a drug or antibody, or genetically) to support their necessity, and then replace their function selectively to support claims of sufficiency. Pharmacological approaches such as MC stabilizers (cromolyn) or activators (c48/80) have commonly been used to infer a role for MCs. However, both of these drugs can have MC-independent effects on other immune cells (Arumugam et al., 2006; Oka et al., 2012; Schemann et al., 2012). There are also other approaches using recombinant MC proteases, such as tryptase, chymase, and tyrosine kinase inhibitors. However, all of these approaches have potential off-target effects limiting the interpretation of the results (Galli et al., 2015).

As these approaches lack true specificity for MCs, genetic approaches represent a more definitive way to assess the functions of MCs in vivo. Two commonly used genetically

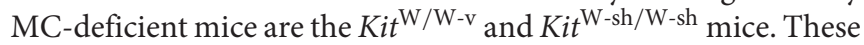
mice have different types of mutations affecting the $c$ - $k i t$ gene that result in a profound deficiency of MCs and melanocytes in both mice. However, both $\mathrm{WBB}^{-} \mathrm{F}_{1}-\mathrm{Kit}^{\mathrm{W} / \mathrm{W}-\mathrm{v}}$ and $\mathrm{C} 57 \mathrm{BL} / 6-$ $K i t^{\mathrm{W}-\mathrm{sh} / \mathrm{W} \text {-sh }}$ also have several other abnormalities within and outside the immune system, including effects on hematopoietic cells other than MCs (Galli et al., 2015). Thus, the differences in the biological responses in these $\mathrm{Kit}^{\mathrm{W} / \mathrm{W}-\mathrm{v}}$ and $\mathrm{Kit}^{\mathrm{W} \text {-sh/W-sh }}$ mice compared with wild type (WT) mice may, in principle, reflect any of the abnormalities in these mice and are not necessarily due to their MC deficiency. However, the MC deficiency in these mice can be selectively "repaired" by the adoptive transfer of in vitro- derived WT or mutant MCs (Nakano et al., 1985; Galli et al., 2005; Grimbaldeston et al., 2005). These in vitro-grown, bone marrow-derived, cultured MCs (BMCMCs) can be administered systemically or locally to create the so-called "MC knock-in mice" (Galli et al., 2015). These engrafted BMCMCs were shown to survive, and function normally, up to 18 weeks in lungs ( $\mathrm{Yu}$ et al., 2006), 12 weeks in the skin (Biggs et al., 2010), and 10 weeks in the meninges (Arac et al., 2014). Moreover, the numbers of MCs in the MC knock-in mice are generally equivalent to those of the WT animals (Yu et al., 2006; Biggs et al., 2010; Arac et al., 2014). MC knock-in mice have been widely used to assess the roles of MCs in several biological events in vivo.

Despite the power of MC knock-in mice, these mice still carry potential problems inherent to c-kit related abnormalities (and other abnormalities in the $\mathrm{Kit}^{\mathrm{W} \text {-sh/W-sh }}$ mice) in the mutant mice. To overcome this issue, MC-deficient mice with normal c-kit function were developed by using MC-specific Cre recombinase approach (Dudeck et al., 2011; Feyerabend et al., 2011; Lilla et al., 2011). Such mice profoundly lack MCs (and to a lesser extent, basophils), but have normal c-kit function and lack the known abnormalities that the c-kit mutant mice have. Moreover, inducible models of MC deficiency were also developed by using the MC-specific Cre recombinase and inducible diphtheria toxin receptor expression (Dudeck et al., 2011; Otsuka et al., 2011; Reber et al., 2014). Injection of diphtheria toxin locally to the site of interest results in profound depletion of local MCs in these mice.

Given all these in vivo models to study MC function (with different pros and cons), one recommended approach has been to use more than one of these models to assess the initial biological responses, and if there are consistent results between the models, then proceeding to further studies (Galli et al., 2015). For additional discussion of these models, we recommend reading this review (Galli et al., 2015).

\section{MENINGEAL MCs EXACERBATE STROKE PATHOLOGY}

We utilized some of these various in vivo models in order to assess the role of MCs in stroke pathology (Arac et al., 2014). $\mathrm{WBB}_{6} \mathrm{~F}_{1}-K i t^{\mathrm{W} / \mathrm{W}-\mathrm{v}}$ mice had significantly smaller infarcts and less brain swelling compared to WT controls at 3 and 14 days after stroke. Systemic engraftment of WT MCs in these c-kit mutant mice resulted in the same extent of injury as the WT mice. In parallel to these results, the MC-deficient Cpa3-Cre; Mc1-1 ${ }^{f l / f l}$ mice (Lilla et al., 2011; MC-deficient mice with normal c-kit function) also had a smaller extent of stroke pathology when compared to their corresponding WT counterparts. Both mouse models also showed a similar MC-dependent pattern for myeloid, but not lymphoid, cell numbers in the brain at 3 days after stroke. Together, these data from two different types of in vivo mouse models of genetically-determined $\mathrm{MC}$ deficiency provide strong support that MCs play an important role in worsening the brain injury after stroke.

Because the MC deficiencies in both of these models are in all examined tissues, it is hard to discern which population of MCs might be critical for this effect. Thus, we compared 

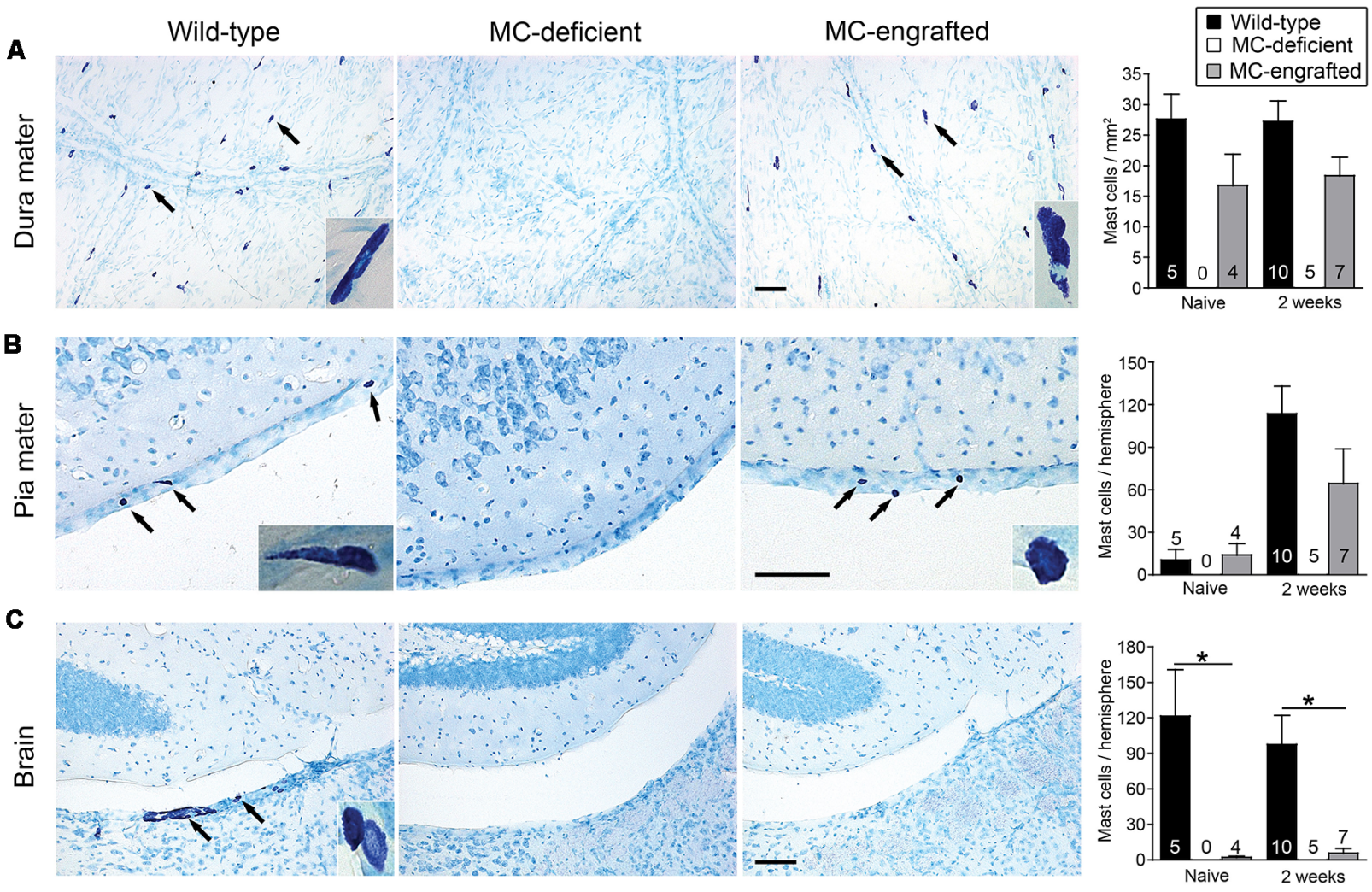

FIGURE 2 | Location of MCs in the central nervous system (CNS). Representative toluidine blue-stained images of and quantification of MCs in dura mater (A), pia mater (B), and brain parenchyma (C) of MC-deficient WBB6F1-Kit W/W-v mice and the corresponding wild type (WT) mice and MC-engrafted Kit ${ }^{\mathrm{W} / \mathrm{W}-\mathrm{v}}$ mice. MCs stain purple with toluidine blue; arrows indicate representative MCs. Insets show magnified images of MCs in each tissue. Data are expressed as means+SEM. The number of mice in each group is indicated in (or over) each bar. ${ }^{*} P<0.05$. Scale bars: $100 \mathrm{~mm}$ (A-C). Reprinted from Arac et al. (2014) with permission from Elsevier.

the number of CNS MCs in the MC-engrafted $\mathrm{WBB}_{6} \mathrm{~F}_{1}$ $\mathrm{Kit}^{\mathrm{W} / \mathrm{W}-\mathrm{v}}$ mice to those of $\mathrm{WT}\left(\mathrm{WBB} \mathrm{F}_{1}-\mathrm{Kit}^{+/+}\right)$mice. Both WT mice and MC-engrafted mice had similar numbers of MCs in the dura and pia mater both before and 2 weeks after stroke (Figures 2A,B). In contrast, the brain parenchyma of the MC-engrafted mice had either no or substantially fewer MCs (Figure 2C). These data strongly suggest that brain parenchymal MCs are not responsible for the MC-dependent worsening of the stroke pathology observed in this mouse model. It instead suggests a potential role for meningeal MCs in modulating this response. Moreover, the density of MCs in the dura mater of both WT and MC-engrafted mice $\left(15-27\right.$ cells $\left./ \mathrm{mm}^{2}\right)$ is similar to that in humans (Varatharaj et al., 2012; 11-23 cells $/ \mathrm{mm}^{2}$ ). In order to calculate these dural MC densities, we used dura mater whole mount preparations (Figure 2A). This whole mount preparation of dura mater was also later used to identify the meningeal lymphatics (Louveau et al., 2015b, 2018a).

To test whether the meningeal MCs are sufficient in modulating the MC-dependent stroke pathology, we engrafted BMCMCs locally into the meninges. With a modified intracranial injection method, the MCs engraft only in the meninges and the number of meningeal MCs in MC-engrafted animals are similar to those of the WT mice (Sayed et al., 2010; Arac et al., 2014). After meningeal engraftment of MCs, MC-engrafted mice developed significantly worse injury after stroke (Arac et al., 2014). This provides strong evidence that the meningeal MCs are sufficient to elicit the MC-dependent effects in stroke pathology. Moreover, we found by microarray analysis of the dura of MC-deficient $\mathrm{WBB} \mathrm{F}_{1}-K i t^{\mathrm{W}} / \mathrm{W}-\mathrm{v}$ mice, the corresponding WT $\left(\mathrm{WBB}_{1}-\mathrm{Kit}^{+/+}\right)$mice, and $\mathrm{WBB}_{1} \mathrm{~F}_{1}$ $K i t^{\mathrm{W} / \mathrm{W}-\mathrm{v}}$ mice which had been engrafted in the meninges with WT BMCMCs (unpublished data), that the meninges are a site of inflammation-related activity after stroke and that the meningeal inflammatory gene response to stroke is modulated, at least in part, by MCs (Figure 3A). We found that many stroke-activated genes in the meninges are involved in the regulation of inflammatory and immune system processes. These include cytokines, chemokines, cell adhesion molecules, immune signaling receptors and extracellular matrix remodeling molecules, all of which are known to contribute to leukocyte migration and activation (Figure 3B). Notably, we found that many of the strokeinduced gene changes involved in inflammation were either absent or exhibited a smaller response in MC-deficient mice, but were recapitulated when MCs were engrafted 

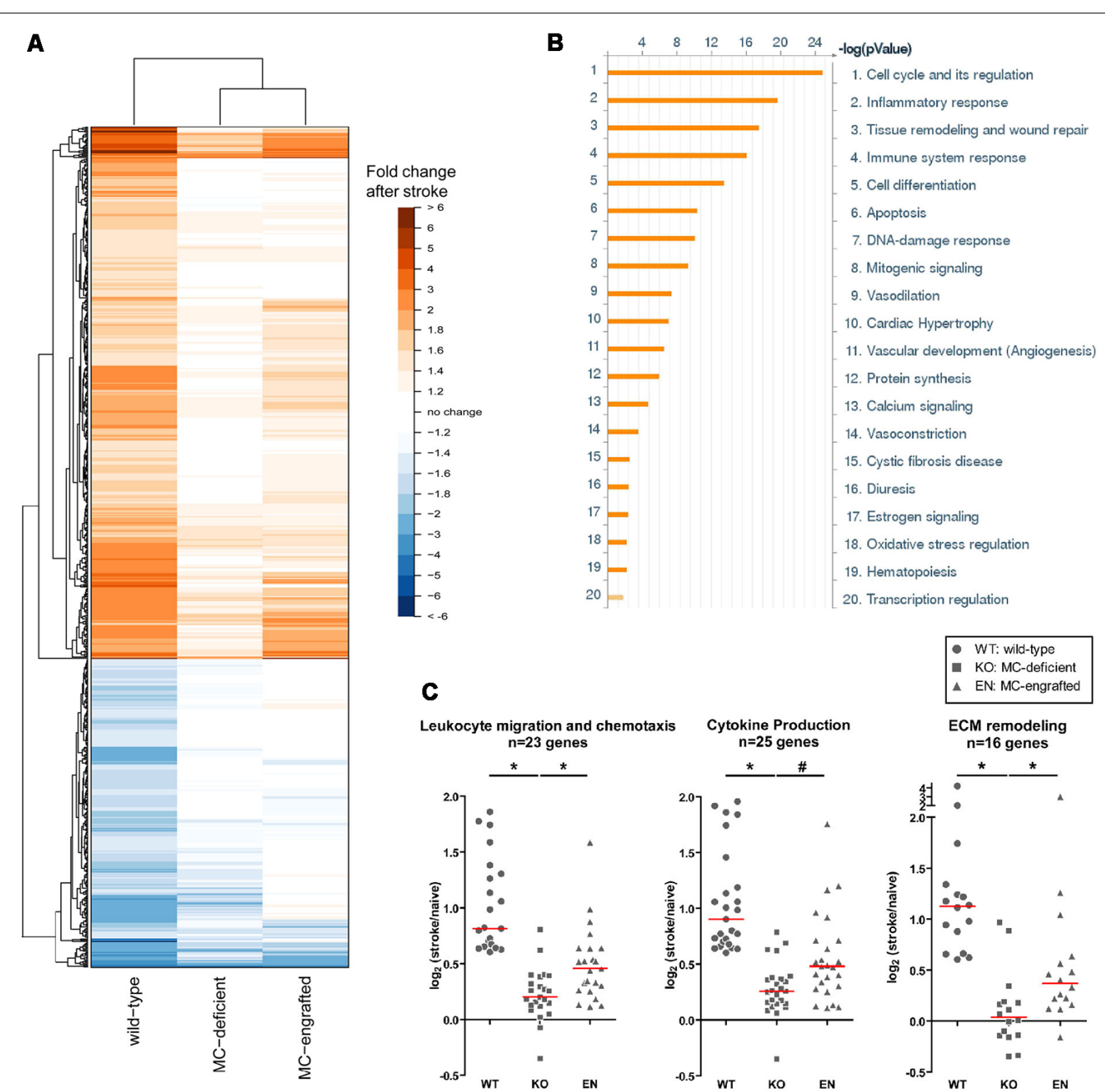

FIGURE 3 | Meningeal gene expression changes after stroke. (A) Heatmap showing the fold-change in expression of genes significantly changed $(p<0.05)$ after

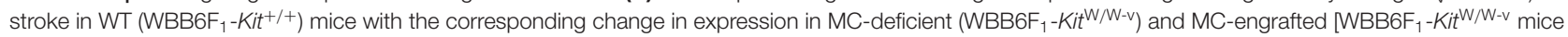
which had been engrafted in the meninges with WT bone marrow-derived, cultured MCs (BMCMCs)] mice (irrespective of whether the gene changes in these two groups after stroke reach significance). The genes represented are those with an absolute fold-change after stroke of $\geq 1.5$ in WT mice. (B) Pathway map of the functional grouping of genes that were significantly upregulated after stroke in WT mice. (C) Dot plots showing the $\log _{2}$ fold-change in expression after stroke of genes within the indicated gene ontology groups in each of three mouse groups. The genes represented in each gene ontology group were significantly upregulated after stroke in WT mice, with a fold-change of $\geq 1.5$. Each data point within a mouse group represents a different gene. Red line indicates median. ${ }^{*} p<0.05$; $\# p=0.05$.

into these mice, consistent with the idea that MCs can modulate the meningeal inflammatory gene changes after stroke (Figure 3C).

In order to identify the MC-derived products that influence stroke pathology, BMCMCs derived from two candidate factordeficient mice (IL-6 and CCL7) were injected into the meninges of MC-deficient mice (Arac et al., 2014). We found that mice meningeally engrafted with BMCMCs which lack IL-6 failed to demonstrate MC-dependent responses in stroke pathology compared to the WT BMCMC engrafted mice. By contrast, MC-derived CCL7 had less of an effect on stroke pathology (Arac et al., 2014). This demonstrates how meningeal MC-derived IL-6 can, in part, explain the MC-dependent effects in stroke pathology.
There are several questions that require further studies. For example, how does the meningeal MC-derived IL-6 execute its function to exacerbate stroke pathology? What downstream pathways are involved in this biological response? Does it alter the meningeal access of immune cells to the brain? What are its effects on brain meningeal lymphatics? Likewise, what are the mechanisms involved in stimulating the meningeal MCs to release IL-6 after a stroke? Are there other MC-derived factors that also might be involved in worsening the stroke pathology? Contrary to these, could anti-coagulative effects of MC-derived heparin proteoglycan and/or proteases have effects in dissolving the blood clot in ischemic stroke? Moreover, there could also be other, yet to be identified, meningeal MC-derived products that are important in the 
repair process after stroke. Thus, one should be cautious in directly targeting MCs as a therapeutic for stroke (Ocak et al., 2018). These and many other questions need to be investigated to better understand the role of meningeal MCs in stroke pathology.

\section{OPPORTUNITIES AND CHALLENGES FOR FUTURE}

Immune responses after stroke are complex with many elements involved, and it is not the focus of this article to comprehensively review that literature; interested readers can find up-to-date review articles on this topic (McCombe and Read, 2008; Iadecola and Anrather, 2011; Macrez et al., 2011; Lambertsen et al., 2018; Rayasam et al., 2018). The post-stroke immune response potentially holds very promising targets for therapeutic interventions for stroke (Arac et al., 2011; Macrez et al., 2011). However, these post-stroke immune events have not been well characterized, with many of the immune responses potentially having dual roles. Development of new and effective therapeutics for stroke will require detailed, mechanistic studies before consideration of specific approaches for therapeutic intervention. Here, we have discussed recent advances in post-stroke immune response with a particular focus on the role of meningeal MCs. Given the increasing importance and key roles of meninges in the regulation of brain-immune interactions (Rua and McGavern, 2018), meningeal MCs are ideally located to play potentially key roles in these interactions. As MCs have diverse roles in many immune responses (Galli et al., 2005, 2008), their key location in the meninges makes them potentially important players in the regulation of immune responses in the brain during health and disease.

\section{REFERENCES}

Albers, G. W., Marks, M. P., Kemp, S., Christensen, S., Tsai, J. P., OrtegaGutierrez, S., et al. (2018). Thrombectomy for stroke at 6 to 16 hours with selection by perfusion imaging. N. Engl. J. Med. 378, 708-718. doi: 10.1056/NEJMoa1713973

Allen, C., Thornton, P., Denes, A., McColl, B. W., Pierozynski, A., Monestier, M., et al. (2012). Neutrophil cerebrovascular transmigration triggers rapid neurotoxicity through release of proteases associated with decondensed DNA. J. Immunol. 189, 381-392. doi: 10.4049/jimmunol.1200409

Androdias, G., Reynolds, R., Chanal, M., Ritleng, C., Confavreux, C., and Nataf, S. (2010). Meningeal T cells associate with diffuse axonal loss in multiple sclerosis spinal cords. Ann. Neurol. 68, 465-476. doi: 10.1002/ana.22054

Anrather, J., and Iadecola, C. (2016). Inflammation and stroke: an overview. Neurotherapeutics 13, 661-670. doi: 10.1007/s13311-016-0483-x

Arac, A., Brownell, S. E., Rothbard, J. B., Chen, C., Ko, R. M., Pereira, M. P., et al. (2011). Systemic augmentation of $\alpha \mathrm{B}$-crystallin provides therapeutic benefit twelve hours post-stroke onset via immune modulation. Proc. Natl. Acad. Sci. U S A 108, 13287-13292. doi: 10.1073/pnas.1107368108

Arac, A., Grimbaldeston, M. A., Nepomuceno, A. R., Olayiwola, O., Pereira, M. P., Nishiyama, Y., et al. (2014). Evidence that meningeal mast cells can worsen stroke pathology in mice. Am. J. Pathol. 184, 2493-2504. doi: 10.1016/j.ajpath. 2014.06.003

Arumugam, T., Ramachandran, V., and Logsdon, C. D. (2006). Effect of cromolyn on S100P interactions with RAGE and pancreatic cancer growth and invasion in mouse models. J. Natl. Cancer Inst. 98, 1806-1818. doi: 10.1093/jnci/djj498
Identifying the roles of several immune elements in stroke pathology is critical for the development of effective therapeutics. Fortunately, there are many advanced immunological tools to perform mechanistic studies. Without such detailed characterization of post-stroke immune responses, performing clinical tests of potential targets will likely result in failures, and may decrease the enthusiasm for future studies.

\section{DATA AVAILABILITY}

The datasets generated for this study are available on request to the corresponding author.

\section{AUTHOR CONTRIBUTIONS}

AA wrote the initial draft of the review. All authors contributed to revising the manuscript, reading and approving the submitted version.

\section{FUNDING}

This work was supported in part by Stanford School of Medicine Dean's Fellowship (Neizer Funds; AA); National Institutes of Health (NIH) grants NS065723 (AA), NS109315 (AA), NS080062 and NS37520-08 (GS) and AI070813, AI023990, and CA072074 (SG); Russell and Elizabeth Siegelman (GS); Bernard and Ronni Lacroute (GS); William Randolph Hearst Foundation (GS); an Australian NHMRC Career Development Fellowship and NHMRC project grants (MG).

\section{ACKNOWLEDGMENTS}

We thank Christine Plant for assistance with the manuscript.

Aspelund, A., Antila, S., Proulx, S. T., Karlsen, T. V., Karaman, S., Detmar, M., et al. (2015). A dural lymphatic vascular system that drains brain interstitial fluid and macromolecules. J. Exp. Med. 212, 991-999. doi: 10.1084/jem.201 42290

Benakis, C., Llovera, G., and Liesz, A. (2018). The meningeal and choroidal infiltration routes for leukocytes in stroke. Ther. Adv. Neurol. Disord. 11:1756286418783708. doi: 10.1177/1756286418783708

Benjamin, E. J., Virani, S. S., Callaway, C. W., Chamberlain, A. M., Chang, A. R., Cheng, S., et al. (2018). Heart disease and stroke statistics-2018 update: a report from the american heart association. Circulation 137, e67-e492. doi: 10.1161/CIR.0000000000000558

Biggs, L., Yu, C., Fedoric, B., Lopez, A. F., Galli, S. J., and Grimbaldeston, M. A. (2010). Evidence that vitamin D(3) promotes mast cell-dependent reduction of chronic UVB-induced skin pathology in mice. J. Exp. Med. 207, 455-463. doi: 10.1084/jem.20091725

Biran, V., Cochois, V., Karroubi, A., Arrang, J. M., Charriaut-Marlangue, C., and Heron, A. (2008). Stroke induces histamine accumulation and mast cell degranulation in the neonatal rat brain. Brain Pathol. 18, 1-9. doi: 10.1111/j. 1750-3639.2007.00092.x

Chen, Y., Bodhankar, S., Murphy, S. J., Vandenbark, A. A., Alkayed, N. J., and Offner, H. (2012). Intrastriatal B-cell administration limits infarct size after stroke in B-cell deficient mice. Metab. Brain Dis. 27, 487-493. doi: 10.1007/s11011-012-9317-7

Christoffersson, G., Vågesjö, E., Vandooren, J., Liden, M., Massena, S. Reinert, R. B., et al. (2012). VEGF-A recruits a proangiogenic MMP-9delivering neutrophil subset that induces angiogenesis in transplanted 
hypoxic tissue. Blood 120, 4653-4662. doi: 10.1182/blood-2012-04421040

Clarkson, B. D., Ling, C., Shi, Y., Harris, M. G., Rayasam, A., Sun, D., et al. (2014). T cell-derived interleukin (IL)-21 promotes brain injury following stroke in mice. J. Exp. Med. 211, 595-604. doi: 10.1084/jem.20131377

Clausen, B. H., Lambertsen, K. L., Babcock, A. A., Holm, T. H., DagnaesHansen, F., and Finsen, B. (2008). Interleukin-1beta and tumor necrosis factor-alpha are expressed by different subsets of microglia and macrophages after ischemic stroke in mice. J. Neuroinflammation 5:46. doi: 10.1186/17422094-5-46

Cuartero, M. I., Ballesteros, I., Moraga, A., Nombela, F., Vivancos, J., Hamilton, J. A., et al. (2013). N2 neutrophils, novel players in brain inflammation after stroke: modulation by the PPAR $\gamma$ agonist rosiglitazone. Stroke 44, 3498-3508. doi: 10.1161/strokeaha.113.002470

Derecki, N. C., Cardani, A. N., Yang, C. H., Quinnies, K. M., Crihfield, A., Lynch, K. R., et al. (2010). Regulation of learning and memory by meningeal immunity: a key role for IL-4. J. Exp. Med. 207, 1067-1080. doi: 10.1084/jem. 20091419

Dimlich, R. V., Keller, J. T., Strauss, T. A., and Fritts, M. J. (1991). Linear arrays of homogeneous mast cells in the dura mater of the rat. J. Neurocytol. 20, 485-503. doi: $10.1007 / \mathrm{bf} 01252276$

Doyle, K. P., Quach, L. N., Sole, M., Axtell, R. C., Nguyen, T. V., Soler-Llavina, G. J., et al. (2015). B-lymphocyte-mediated delayed cognitive impairment following stroke. J. Neurosci. 35, 2133-2145. doi: 10.1523/JNEUROSCI.4098-14.2015

Dudeck, A., Dudeck, J., Scholten, J., Petzold, A., Surianarayanan, S., Kohler, A., et al. (2011). Mast cells are key promoters of contact allergy that mediate the adjuvant effects of haptens. Immunity 34, 973-984. doi: 10.1016/j.immuni. 2011.03.028

Feyerabend, T. B., Weiser, A., Tietz, A., Stassen, M., Harris, N., Kopf, M., et al. (2011). Cre-mediated cell ablation contests mast cell contribution in models of antibody- and $\mathrm{T}$ cell-mediated autoimmunity. Immunity 35, 832-844. doi: 10.1016/j.immuni.2011.09.015

Fisher, M., and Saver, J. L. (2015). Future directions of acute ischaemic stroke therapy. Lancet Neurol. 14, 758-767. doi: 10.1016/s1474-4422(15)00054-x

Galli, S. J., Borregaard, N., and Wynn, T. A. (2011). Phenotypic and functional plasticity of cells of innate immunity: macrophages, mast cells and neutrophils. Nat. Immunol. 12, 1035-1044. doi: 10.1038/ni.2109

Galli, S. J., Grimbaldeston, M., and Tsai, M. (2008). Immunomodulatory mast cells: negative, as well as positive, regulators of immunity. Nat. Rev. Immunol. 8, 478-486. doi: 10.1038/nri2327

Galli, S. J., Kalesnikoff, J., Grimbaldeston, M. A., Piliponsky, A. M., Williams, C. M., and Tsai, M. (2005). Mast cells as "tunable" effector and immunoregulatory cells: recent advances. Annu. Rev. Immunol. 23, 749-786. doi: 10.1146/annurev.immunol.21.120601.141025

Galli, S. J., and Tsai, M. (2012). IgE and mast cells in allergic disease. Nat. Med. 18, 693-704. doi: 10.1038/nm.2755

Galli, S. J., Tsai, M., Marichal, T., Tchougounova, E., Reber, L. L., and Pejler, G. (2015). Approaches for analyzing the roles of mast cells and their proteases in vivo. Adv. Immunol. 126, 45-127. doi: 10.1016/bs.ai.2014.11.002

Garcia-Bonilla, L., Faraco, G., Moore, J., Murphy, M., Racchumi, G., Srinivasan, J., et al. (2016). Spatio-temporal profile, phenotypic diversity and fate of recruited monocytes into the post-ischemic brain. J. Neuroinflammation 13:285. doi: 10.1186/s12974-016-0750-0

George, P. M., and Steinberg, G. K. (2015). Novel stroke therapeutics: unraveling stroke pathophysiology and its impact on clinical treatments. Neuron 87, 297-309. doi: 10.1016/j.neuron.2015.05.041

Grimbaldeston, M. A., Chen, C. C., Piliponsky, A. M., Tsai, M., Tam, S. Y., and Galli, S. J. (2005). Mast cell-deficient W-sash c-kit mutant Kit W-sh/W-sh mice as a model for investigating mast cell biology in vivo. Am. J. Pathol. 167, 835-848. doi: 10.1016/S0002-9440(10)62055-X

Grimbaldeston, M. A., Nakae, S., Kalesnikoff, J., Tsai, M., and Galli, S. J. (2007). Mast cell-derived interleukin 10 limits skin pathology in contact dermatitis and chronic irradiation with ultraviolet B. Nat. Immunol. 8, 1095-1104. doi: $10.1038 /$ ni1503

Herisson, F., Frodermann, V., Courties, G., Rohde, D., Sun, Y., Vandoorne, K., et al. (2018). Direct vascular channels connect skull bone marrow and the brain surface enabling myeloid cell migration. Nat. Neurosci. 21, 1209-1217. doi: 10.1038/s41593-018-0213-2
Iadecola, C., and Anrather, J. (2011). The immunology of stroke: from mechanisms to translation. Nat. Med. 17, 796-808. doi: 10.1038/nm.2399

Ito, D., Tanaka, K., Suzuki, S., Dembo, T., and Fukuuchi, Y. (2001). Enhanced expression of Iba1, ionized calcium-binding adapter molecule 1, after transient focal cerebral ischemia in rat brain. Stroke 32, 1208-1215. doi: 10.1161/01.str. 32.5.1208

Jickling, G. C., Liu, D., Ander, B. P., Stamova, B., Zhan, X., and Sharp, F. R. (2015). Targeting neutrophils in ischemic stroke: translational insights from experimental studies. J. Cereb. Blood Flow Metab. 35, 888-901. doi: $10.1038 / \mathrm{jcbfm} .2015 .45$

Jin, Y., Silverman, A. J., and Vannucci, S. J. (2009). Mast cells are early responders after hypoxia-ischemia in immature rat brain. Stroke 40, 3107-3112. doi: 10.1161/strokeaha.109.549691

Knowland, D., Arac, A., Sekiguchi, K. J., Hsu, M., Lutz, S. E., Perrino, J., et al. (2014). Stepwise recruitment of transcellular and paracellular pathways underlies blood-brain barrier breakdown in stroke. Neuron 82, 603-617. doi: 10.1016/j.neuron.2014.03.003

Kwong, B., Rua, R., Gao, Y., Flickinger, J. Jr., Wang, Y., Kruhlak, M. J., et al. (2017). T-bet-dependent NKp46 ${ }^{+}$innate lymphoid cells regulate the onset of $\mathrm{T}_{H} 17$ induced neuroinflammation. Nat. Immunol. 18, 1117-1127. doi: 10.1038/ ni. 3816

Lambertsen, K. L., Clausen, B. H., Babcock, A. A., Gregersen, R., Fenger, C., Nielsen, H. H., et al. (2009). Microglia protect neurons against ischemia by synthesis of tumor necrosis factor. J. Neurosci. 29, 1319-1330. doi: 10.1523/jneurosci.5505-08.2009

Lambertsen, K. L., Finsen, B., and Clausen, B. H. (2018). Poststroke inflammation-target or tool for therapy? Acta Neuropathol. doi: 10.1007/s00401-018-1930-z [Epub ahead of print].

Lambertsen, K. L., Meldgaard, M., Ladeby, R., and Finsen, B. (2005). A quantitative study of microglial-macrophage synthesis of tumor necrosis factor during acute and late focal cerebral ischemia in mice. J. Cereb. Blood Flow Metab. 25, 119-135. doi: 10.1038/sj.jcbfm.9600014

Liesz, A., Karcher, S., and Veltkamp, R. (2013a). Spectratype analysis of clonal T cell expansion in murine experimental stroke. J. Neuroimmunol. 257, 46-52. doi: 10.1016/j.jneuroim.2013.01.013

Liesz, A., Zhou, W., Na, S. Y., Hammerling, G. J., Garbi, N., Karcher, S., et al. (2013b). Boosting regulatory $\mathrm{T}$ cells limits neuroinflammation in permanent cortical stroke. J. Neurosci. 33, 17350-17362. doi: 10.1523/jneurosci.490112.2013

Liesz, A., Sun, L., Zhou, W., Schwarting, S., Mracsko, E., Zorn, M., et al. (2011a). FTY720 reduces post-ischemic brain lymphocyte influx but does not improve outcome in permanent murine cerebral ischemia. PLoS One 6:e21312. doi: 10.1371/journal.pone.0021312

Liesz, A., Zhou, W., Mracsko, E., Karcher, S., Bauer, H., Schwarting, S., et al. (2011b). Inhibition of lymphocyte trafficking shields the brain against deleterious neuroinflammation after stroke. Brain 134, 704-720. doi: 10.1093/brain/awr008

Liesz, A., Suri-Payer, E., Veltkamp, C., Doerr, H., Sommer, C., Rivest, S., et al. (2009). Regulatory $\mathrm{T}$ cells are key cerebroprotective immunomodulators in acute experimental stroke. Nat. Med. 15, 192-199. doi: 10.1038/nm.1927

Lilla, J. N., Chen, C. C., Mukai, K., BenBarak, M. J., Franco, C. B., Kalesnikoff, J., et al. (2011). Reduced mast cell and basophil numbers and function in Cpa3-Cre; Mcl-1fl/fl mice. Blood 118, 6930-6938. doi: 10.1182/blood-2011-03343962

Lindsberg, P. J., Strbian, D., and Karjalainen-Lindsberg, M. L. (2010). Mast cells as early responders in the regulation of acute blood-brain barrier changes after cerebral ischemia and hemorrhage. J. Cereb. Blood Flow Metab. 30, 689-702. doi: $10.1038 /$ jcbfm.2009.282

Louveau, A., Filiano, A. J., and Kipnis, J. (2018a). Meningeal whole mount preparation and characterization of neural cells by flow cytometry. Curr. Protoc. Immunol. 121:e50. doi: 10.1002/cpim.50

Louveau, A., Herz, J., Alme, M. N., Salvador, A. F., Dong, M. Q., Viar, K. E., et al. (2018b). CNS lymphatic drainage and neuroinflammation are regulated by meningeal lymphatic vasculature. Nat. Neurosci. 21, 1380-1391. doi: 10.1038/s41593-018-0227-9

Louveau, A., Harris, T. H., and Kipnis, J. (2015a). Revisiting the mechanisms of CNS immune privilege. Trends Immunol. 36, 569-577. doi: 10.1016/j.it.2015. 08.006 
Louveau, A., Smirnov, I., Keyes, T. J., Eccles, J. D., Rouhani, S. J., Peske, J. D., et al. (2015b). Structural and functional features of central nervous system lymphatic vessels. Nature 523, 337-341. doi: 10.1038/nature14432

Macrez, R., Ali, C., Toutirais, O., Le Mauff, B., Defer, G., Dirnagl, U., et al. (2011). Stroke and the immune system: from pathophysiology to new therapeutic strategies. Lancet Neurol. 10, 471-480. doi: 10.1016/s1474-4422(11) 70066-7

Mattila, O. S., Strbian, D., Saksi, J., Pikkarainen, T. O., Rantanen, V., Tatlisumak, T., et al. (2011). Cerebral mast cells mediate blood-brain barrier disruption in acute experimental ischemic stroke through perivascular gelatinase activation. Stroke 42, 3600-3605. doi: 10.1161/strokeaha.111. 632224

McCombe, P. A., and Read, S. J. (2008). Immune and inflammatory responses to stroke: good or bad? Int. J. Stroke 3, 254-265. doi: 10.1111/j.1747-4949.2008. 00222.x

McKittrick, C. M., Lawrence, C. E., and Carswell, H. V. (2015). Mast cells promote blood brain barrier breakdown and neutrophil infiltration in a mouse model of focal cerebral ischemia. J. Cereb. Blood Flow Metab. 35, 638-647. doi: $10.1038 /$ jcbfm.2014.239

Metz, M., Piliponsky, A. M., Chen, C. C., Lammel, V., Abrink, M., Pejler, G., et al. (2006). Mast cells can enhance resistance to snake and honeybee venoms. Science 313, 526-530. doi: 10.1126/science.1128877

Moskowitz, M. A., Lo, E. H., and Iadecola, C. (2010). The science of stroke: mechanisms in search of treatments. Neuron 67, 181-198. doi: 10.1016/j. neuron.2010.07.002

Mracsko, E., Liesz, A., Stojanovic, A., Lou, W. P., Osswald, M., Zhou, W., et al. (2014). Antigen dependently activated cluster of differentiation 8-positive T cells cause perforin-mediated neurotoxicity in experimental stroke. J. Neurosci. 34, 16784-16795. doi: 10.1523/jneurosci.1867-14.2014

Mukai, K., Tsai, M., Saito, H., and Galli, S. J. (2018). Mast cells as sources of cytokines, chemokines, and growth factors. Immunol. Rev. 282, 121-150. doi: 10.1111/imr.12634

Na, S. Y., Mracsko, E., Liesz, A., Hunig, T., and Veltkamp, R. (2015). Amplification of regulatory $\mathrm{T}$ cells using a CD28 superagonist reduces brain damage after ischemic stroke in mice. Stroke 46, 212-220. doi: 10.1161/strokeaha.114.007756

Nakano, T., Sonoda, T., Hayashi, C., Yamatodani, A., Kanayama, Y., Yamamura, T., et al. (1985). Fate of bone marrow-derived cultured mast cells after intracutaneous, intraperitoneal and intravenous transfer into genetically mast cell-deficient W/Wv mice. Evidence that cultured mast cells can give rise to both connective tissue type and mucosal mast cells. J. Exp. Med. 162, 1025-1043. doi: 10.1084/jem.162.3.1025

Neher, J. J., Emmrich, J. V., Fricker, M., Mander, P. K., Thery, C., and Brown, G. C. (2013). Phagocytosis executes delayed neuronal death after focal brain ischemia. Proc. Natl. Acad. Sci. U S A 110, E4098-E4107. doi: 10.1073/pnas. 1308679110

Neumann, H., Kotter, M. R., and Franklin, R. J. (2009). Debris clearance by microglia: an essential link between degeneration and regeneration. Brain 132, 288-295. doi: 10.1093/brain/awn109

Neumann, J., Riek-Burchardt, M., Herz, J., Doeppner, T. R., König, R., Hütten, H., et al. (2015). Very-late-antigen-4 (VLA-4)-mediated brain invasion by neutrophils leads to interactions with microglia, increased ischemic injury and impaired behavior in experimental stroke. Acta Neuropathol. 129, 259-277. doi: 10.1007/s00401-014-1355-2

Nogueira, R. G., Jadhav, A. P., Haussen, D. C., Bonafe, A., Budzik, R. F., Bhuva, P., et al. (2018). Thrombectomy 6 to 24 hours after stroke with a mismatch between deficit and infarct. N. Engl. J. Med. 378, 11-21. doi: 10.1056/NEJMoa1706442

Ocak, U., Ocak, P. E., Wang, A., Zhang, J. H., Boling, W., Wu, P., et al. (2018). Targeting mast cell as a neuroprotective strategy. Brain Inj. doi: 10.1080/02699052.2018.1556807 [Epub ahead of print].

Oka, T., Kalesnikoff, J., Starkl, P., Tsai, M., and Galli, S. J. (2012). Evidence questioning cromolyn's effectiveness and selectivity as a 'mast cell stabilizer' in mice. Lab. Invest. 92, 1472-1482. doi: 10.1038/labinvest.2012.116

Otsuka, A., Kubo, M., Honda, T., Egawa, G., Nakajima, S., Tanizaki, H., et al. (2011). Requirement of interaction between mast cells and skin dendritic cells to establish contact hypersensitivity. PLoS One 6:e25538. doi: 10.1371/journal. pone. 0025538

Perego, C., Fumagalli, S., and De Simoni, M. G. (2011). Temporal pattern of expression and colocalization of microglia/macrophage phenotype markers following brain ischemic injury in mice. J. Neuroinflammation 8:174 doi: 10.1186/1742-2094-8-174

Perez-de-Puig, I., Miró-Mur, F., Ferrer-Ferrer, M., Gelpi, E., Pedragosa, J., Justicia, C., et al. (2015). Neutrophil recruitment to the brain in mouse and human ischemic stroke. Acta Neuropathol. 129, 239-257. doi: 10.1007/s00401014-1381-0

Rayasam, A., Hsu, M., Kijak, J. A., Kissel, L., Hernandez, G., Sandor, M., et al. (2018). Immune responses in stroke: how the immune system contributes to damage and healing after stroke and how this knowledge could be translated to better cures? Immunology 154, 363-376. doi: 10.1111/imm.12918

Reber, L. L., Marichal, T., Sokolove, J., Starkl, P., Gaudenzio, N., Iwakura, Y., et al. (2014). Contribution of mast cell-derived interleukin-1 $\beta$ to uric acid crystal-induced acute arthritis in mice. Arthritis Rheumatol. 66, 2881-2891. doi: $10.1002 /$ art. 38747

Ren, X., Akiyoshi, K., Dziennis, S., Vandenbark, A. A., Herson, P. S., Hurn, P. D., et al. (2011). Regulatory B cells limit CNS inflammation and neurologic deficits in murine experimental stroke. J. Neurosci. 31, 8556-8563. doi: 10.1523/JNEUROSCI.1623-11.2011

Rua, R., and McGavern, D. B. (2018). Advances in meningeal immunity. Trends Mol. Med. 24, 542-559. doi: 10.1016/j.molmed.2018.04.003

Sayed, B. A., Christy, A. L., Walker, M. E., and Brown, M. A. (2010). Meningeal mast cells affect early $\mathrm{T}$ cell central nervous system infiltration and blood-brain barrier integrity through TNF: a role for neutrophil recruitment? J. Immunol. 184, 6891-6900. doi: 10.4049/jimmunol.1000126

Schäfer, B., Piliponsky, A. M., Oka, T., Song, C. H., Gerard, N. P., Gerard, C., et al. (2013). Mast cell anaphylatoxin receptor expression can enhance IgE-dependent skin inflammation in mice. J. Allergy Clin. Immunol. 131, 541.e9-548.e9. doi: 10.1016/j.jaci.2012.05.009

Schemann, M., Kugler, E. M., Buhner, S., Eastwood, C., Donovan, J., Jiang, W., et al. (2012). The mast cell degranulator compound 48/80 directly activates neurons. PLoS One 7:e52104. doi: 10.1371/journal.pone.0052104

Schmidt, A., Strecker, J. K., Hucke, S., Bruckmann, N. M., Herold, M., Mack, M., et al. (2017). Targeting different monocyte/macrophage subsets has no impact on outcome in experimental stroke. Stroke 48, 1061-1069. doi: 10.1161/strokeaha.116.015577

Schuhmann, M. K., Kraft, P., Stoll, G., Lorenz, K., Meuth, S. G., Wiendl, H. et al. (2015). CD28 superagonist-mediated boost of regulatory $\mathrm{T}$ cells increases thrombo-inflammation and ischemic neurodegeneration during the acute phase of experimental stroke. J. Cereb. Blood Flow Metab. 35, 6-10. doi: $10.1038 /$ jcbfm.2014.175

Schuhmann, M. K., Langhauser, F., Kraft, P., and Kleinschnitz, C. (2017). B cells do not have a major pathophysiologic role in acute ischemic stroke in mice. J. Neuroinflammation 14:112. doi: 10.1186/s12974-017-0890-x

Shechter, R., London, A., and Schwartz, M. (2013). Orchestrated leukocyte recruitment to immune-privileged sites: absolute barriers versus educational gates. Nat. Rev. Immunol. 13, 206-218. doi: 10.1038/nri3391

Shichita, T., Sugiyama, Y., Ooboshi, H., Sugimori, H., Nakagawa, R., Takada, I., et al. (2009). Pivotal role of cerebral interleukin-17-producing $\gamma \delta \mathrm{T}$ cells in the delayed phase of ischemic brain injury. Nat. Med. 15, 946-950. doi: 10.1038/nm.1999

Strbian, D., Karjalainen-Lindsberg, M. L., Kovanen, P. T., Tatlisumak, T., and Lindsberg, P. J. (2007). Mast cell stabilization reduces hemorrhage formation and mortality after administration of thrombolytics in experimental ischemic stroke. Circulation 116, 411-418. doi: 10.1161/circulationaha.106.655423

Strbian, D., Karjalainen-Lindsberg, M. L., Tatlisumak, T., and Lindsberg, P. J. (2006). Cerebral mast cells regulate early ischemic brain swelling and neutrophil accumulation. J. Cereb. Blood Flow Metab. 26, 605-612. doi: $10.1038 /$ sj.jcbfm. 9600228

Supajatura, V., Ushio, H., Nakao, A., Akira, S., Okumura, K., Ra, C., et al. (2002). Differential responses of mast cell Toll-like receptors 2 and 4 in allergy and innate immunity. J. Clin. Invest. 109, 1351-1359. doi: 10.1172/jci0214704

Tsai, M., Grimbaldeston, M., and Galli, S. J. (2011). Mast cells and immunoregulation/immunomodulation. Adv. Exp. Med. Biol. 716, 186-211. doi: 10.1007/978-1-4419-9533-9_11

Tsuyama, J., Nakamura, A., Ooboshi, H., Yoshimura, A., and Shichita, T. (2018). Pivotal role of innate myeloid cells in cerebral post-ischemic sterile inflammation. Semin. Immunopathol. 40, 523-538. doi: 10.1007/s00281-0180707-8 
Varatharaj, A., Mack, J., Davidson, J. R., Gutnikov, A., and Squier, W. (2012). Mast cells in the human dura: effects of age and dural bleeding. Childs Nerv. Syst. 28, 541-545. doi: 10.1007/s00381-012-1699-7

Wattananit, S., Tornero, D., Graubardt, N., Memanishvili, T., Monni, E., Tatarishvili, J., et al. (2016). Monocyte-derived macrophages contribute to spontaneous long-term functional recovery after stroke in mice. J. Neurosci. 36, 4182-4195. doi: 10.1523/JNEUROSCI.431715.2016

Yilmaz, G., Arumugam, T. V., Stokes, K. Y., and Granger, D. N. (2006). Role of T lymphocytes and interferon- $\gamma$ in ischemic stroke. Circulation 113, 2105-2112. doi: 10.1161/circulationaha.105.593046

Yu, M., Tsai, M., Tam, S. Y., Jones, C., Zehnder, J., and Galli, S. J. (2006). Mast cells can promote the development of multiple features of chronic asthma in mice. J. Clin. Invest. 116, 1633-1641. doi: 10.1172/jci25702
Conflict of Interest Statement: GS is a consultant for Qool Therapeutics, Peter Lazic US, Inc., and NeuroSave. MG is employed by Genentech Inc.

The remaining authors declare that the research was conducted in the absence of any commercial or financial relationships that could be construed as a potential conflict of interest.

Copyright (C) 2019 Arac, Grimbaldeston, Galli, Bliss and Steinberg. This is an open-access article distributed under the terms of the Creative Commons Attribution License (CC BY). The use, distribution or reproduction in other forums is permitted, provided the original author(s) and the copyright owner(s) are credited and that the original publication in this journal is cited, in accordance with accepted academic practice. No use, distribution or reproduction is permitted which does not comply with these terms. 